\title{
Resenha
}

\section{Açóes Integradas Sobre Drogas: Prevenção, Abordagens e Políticas Públicas}

Ações integradas sobre drogas: prevenção, abordagens e políticas públicas

Telmo Mota Ronzani (Org.).

Juiz de Fora: Editora UFJF, 2013, 448p.
Henrique Pinto Gomide

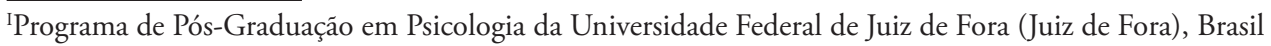

O tema drogas constantemente ocupa espaço nos meios de comunicação e faz parte da agenda política dos mais diversos partidos em todo o país. Devido a sua natureza polêmica, a falta de qualidade das informaçôes divulgadas pela mídia e a baixa disponibilidade de literatura sobre o tema voltada para o público geral, esse assunto é geralmente debatido com preconceitos e visōes estereotipadas. Esses preconceitos e estereótipos não estão difundidos somente na opinião pública, mas também entre os profissionais de saúde, inclusive psicólogos e estudantes de psicologia, o que se deve à falta de disciplinas ofertadas com o tema nos cursos de graduação.

Para oferecer acesso às informaçóes baseadas em evidências aos profissionais da psicologia e aos profissionais que trabalham com o tema, os autores do livro buscaram contemplar diversos domínios de forma integrada. Nota-se uma preocupação em todos os capítulos na explicação dos conceitos básicos abordados, além da apresentação da experiência de atuação no país. Boa parte destes exemplos são resultados de pesquisas, encontrados pelos autores, que possuem formação em diversos campos do conhecimento e são de diversas instituiçôes de pesquisa que estudam a temática.

Os capítulos do livro são organizados em quatro seçôes. Na primeira seção do livro - "Contextualização e epidemiologia do uso de drogas" - são abordados tópicos como as formas de classificaçáo das drogas e seus efeitos farmacológicos no organismo. Também é abordada a epidemiologia do uso de drogas, com apresentação de conceitos básicos e informações sobre a prevalência do uso de drogas no país. Nesta seção, o mito de que as drogas ilícitas, como o crack, causam maiores problemas à sociedade é quebrado. A importância da prevenção primária e secundária é destacada, modalidades de prevenção esquecidas ao concentrarmos o debate político somente no tratamento de dependentes. As abordagens de tratamento são apresentadas para usuários de álcool e tabaco, drogas que causam maiores impactos na sociedade. Ambas abordagens são fundamentadas nos princípios da Entrevista Motivacional (Miller \& Rollnick, 2001) e no Modelo de Prevençáo de Recaídas (Marlatt \& Donnavan, 2005).

$\mathrm{Na}$ segunda seção do livro - "Abordagens preventivas e intervençóes em grupos específicos" são apresentadas intervenções para grupos específicos: mulheres, adolescentes e família. As características desses grupos exigem diferentes estratégias de ação pelos profissionais de saúde. Diferentes tipos de intervenção para adolescentes são avaliados quanto a sua eficácia.

$\mathrm{Na}$ terceira seção - "Aspectos socioculturais do uso de drogas" - são apontadas as evidências que derrubam mitos divulgados quase diariamente pela mídia. Como, por exemplo, a visão de que usuários de drogas ilícitas são os maiores responsáveis pela violência. A forma com que a cobertura jornalística é feita também é abordada. Mostrando que, quando ignorados os fatos, esta pode formar opiniōes erradas e tirar o foco das questóes centrais. Seus potenciais também são abordados, assim como casos em que a cobertura tenha ajudado na melhoria dos indicadores de saúde e na redução do consumo de drogas. Estes dois temas se relacionam diretamente ao terceiro capítulo da seçáo, o estigma social ligado às drogas. $\mathrm{O}$ estigma associado aos usuários de drogas tem sido uma preocupação dos especialistas, por reduzir a busca por ajuda entre os dependentes, que acreditam que a dependência é um problema de cunho moral e não médico. Essa visão moralizante não é restrita somente ao usuário de drogas, mas também inclui os profissionais de saúde e a sociedade como um todo.

A quarta seção - "Políticas e intersetorialidade" aborda as políticas públicas sobre drogas do país e os desafios existentes para implementaçáo nos níveis federal, estadual e municipal. Outro desafio é oferecer atençáo integral aos usuários de álcool, tabaco e outras drogas. No capítulo seguinte são apresentadas estratégias de disseminação e açôes de prevenção para álcool e outras drogas. Além das estratégias, são discutidos os desafios 
e barreiras, além dos resultados das experiências de pesquisas-intervenção no treinamento de profissionais de saúde. Nessa seção, também são discutidas duas atividades preconizadas pelas políticas públicas: a participaçáo e o controle social. Estes conceitos são contextualizados historicamente e reflexóes são aplicadas no cenário atual, em que conselhos sobre drogas são organizados como um espaço central para a melhoria da qualidade dos serviços oferecidos à população. No último capítulo é apresentado o conceito de intersetorialidade, que ocorre entre campos essenciais como o da assistência social, da cultura, da defesa social, do esporte, da educação e da saúde.

O livro cumpre o propósito de abranger diversos temas sobre álcool, tabaco e outras drogas, apresentando discussóes teóricas e evidências de pesquisas realizadas em diversos países e no Brasil.
Certamente, é uma leitura que possibilita a quebra de diversos preconceitos, sendo indicado náo só para psicólogos, mas também para outros profissionais de saúde, jornalistas e a população em geral.

\section{Referências}

Marlatt, A. G., \& Donavan, D. M. (2005). Prevenção da recaída: estratégias de manutenção no tratamento de comportamentos adictivos. Porto Alegre: Artmed.

Miller, W. R., \& Rollnick. S. (2001). Entrevista motivacional: preparando pessoas para a mudança de comportamento. Porto Alegre: Artmed.

Ronzani, T. M. (Org.). (2013). Açôes integradas sobre drogas: prevenção, abordagens e politicas públicas. Juiz de Fora: Editora UFJF. 